\title{
Temperature conditioning in ornamental plant production with a prototype device: root zone cooling in protected environments
}

\author{
Gianluca Burchi, ${ }^{1}$ Sonia Cacini,, Marco Fedrizzi,, Mauro Pagano, ${ }^{2}$ Mirko Guerrieri, ${ }^{2}$ \\ ${ }^{1}$ CRA-VIV Research Unit for Nursery Plant Production and Management of Landscape and \\ Ornamental Plants, Pescia (PT), Italy; ${ }^{2}$ CRA-ING Research Unit for Agricultural Engineering, \\ Monterotondo (Rome), Italy
}

\begin{abstract}
One of the greatest growing costs in greenhouse floriculture is for energy. To reduce energy costs for thermal conditioning was projected an innovative root zone cooling system characterized by two coaxial pipes with hydraulic countercurrent flows. This new system was compared with a traditional system with hydraulic flows cocurrent. The plants were equipped with coolers for obtaining flowering in the summer period by a culture of Alstroemeria spp and were measured energy consumption in each root zone cooling system. The tests also focused on a particular change, made during the tests of previous years, which allows the coaxial system in turning his operation from countercurrent flows to cocurrent flows. The results obtained show that the root zone coaxial cooling system allows to obtain, in comparison to the traditional type, a better temperature uniformity of the root zone ground, both when it is used with countercurrent flows both when it is used with cocurrent flow. The system also allows a slight overall reduction in energy consumption.
\end{abstract}

Correspondence: Marco Fedrizzi, CRA-ING Research Unit for Agricultural Engineering, via della Pascolare 16, 00016 Monterotondo (Rome), Italy. Tel. +39.0690675253 - Fax: +39.0690625591 .

E-mail: mauro.pagano@entecra.it

Key words: cut flowers, greenhouse, energy consumption, root zone cooling.

Acknowledgments: this study is part of the National Research Project "Florovivaismo: LOgistica e Risparmio ENERgetico F.LO.R.ENER.", financed by the Italian Ministry of Agriculture, in order to study the optimisation of energy use along the flower and ornamental plant production and distribution chain.

Contributions: the authors contributed equally.

Conflict of interests: the authors declare no potential conflict of interests

(C) Copyright G. Burchi et al., 2013

Licensee PAGEPress, Italy

Journal of Agricultural Engineering 2013; XLIV(s2):e51

doi:10.4081/jae.2013.s2.e51

This article is distributed under the terms of the Creative Commons Attribution Noncommercial License (by-nc 3.0) which permits any noncommercial use, distribution, and reproduction in any medium, provided the original author(s) and source are credited.

\section{Introduction}

Cultivation of horticultural crops in protected environments is an industry of considerable economic importance in Italy. Greenhouses can greatly increase the productivity of agricultural soil by accelerating and thus shortening the life cycles of many species, both of vegetables and flowers, promoting crop planning and diversification and also the optimization of inputs.

A technique commonly used in greenhouse management is the root zone heating of seeds, cuttings, transplanted seedlings and plants (Roberts and Mears, 1989; Takakura et al., 1994; Diver, 2002). This method allows the cultivation of ornamental species even when temperature is not optimal for plant growth and development. The most widely used technique for root zone heating involves the use of pipes, laid at the bottom of the benches, in which warm water circulates, heated by a heating boiler.

One of the major problems with this technique is the significant reduction of water temperature along the pipeline, especially in the terminal portion where it arrives after yielding heat to the ground. As a consequence, the tube fails in conditioning the cultivation substrate homogeneously and thus development differs between plants placed at the initial or at the final portion of the heating line.

With the aim of reducing the problems described above, research was carried out by the Research Unit for Agricultural Engineering, Monterotondo, Rome (CRA-ING), at the experimental farm of the Research Unit for Nursery Plant Production and Management of Landscape and Ornamental Plants in Pescia (PT), Italy (CRA-VIV).

\section{Materials and methods}

The aim of this work was to test the ability of an innovative root zone cooling system, characterized by the presence of coaxial pipes, to heat homogeneously potted plants placed on benches, in comparison with the traditional method. The tests were conducted in the experimental farm of CRA-VIV, in a greenhouse consisting of a galvanized iron structure with a polycarbonate roof and a fully automated and motorized opening system.

Eight rectangular concrete benches $(0.70 \mathrm{~m}$ width $\mathrm{x} 7.25$ length $\mathrm{m} \mathrm{x}$ $0.30 \mathrm{~m}$ height) were placed on concrete blocks raising them $0.35 \mathrm{~m}$ above the soil level. The interior walls and bottom were coated with polystyrene panels to a thickness of $5 \mathrm{~cm}$.

Two hydraulic systems, a traditional and a coaxial pipes type, were installed in a greenhouse and were originally used, starting in 2008, for carrying out root zone heating tests (Figure 1) in flower cultivation (Fedrizzi et al., 2006). The innovative root zone temperature conditioning system was placed at the bottom of 4 benches. The innovative feature of this system consist in the presence of a pair of coaxial poly- 
ethylene radiant pipes: in the inner pipe flows the cold water coming from a cooling water plant and in the interstice between the two pipes (return line) flows the water returning to it.

The use of coaxial pipes is widespread for general purpose (Carnavos, 1985; Horton et al., 1975), in heat exchange systems or equipment such as air conditioning and refrigeration circuits (Edwards, 1981), in carrying toxic or hazardous gases (Spiegelman, 1992), in pneumatic servo and control systems (Wolf and Reichert, 1995), in dangerous conditions such possibility of air contamination (Wolf, 1996), in thermally insulating systems (Ziemek and Schatz, 1972).

However, nowadays, it's not the same in agriculture because of the lack of specific facilities: in fact to realize the system, it was used an italian patent (Rosati, B., 2004) that allows the connection between the internal and external coaxial pipes through a specific junction element. The baseline consisted of a smaller pipe (diameter $16 \mathrm{~mm}$ ), with the hot water flow inside, and a larger pipe (diameter $32 \mathrm{~mm}$ ), coaxial to the first, through which the water returned to the cooling plant, connected by means of junction elements. The inner tube was inserted manually for the whole length in the outer one that was closed at the end by a cap. The water passed from the inner pipe to the outer one due to the presence of this closure. The contact between the coaxial pipes results in a continuous transfer of thermal energy between the fluid in the inner pipe and the fluid in the outer pipe. Since the flow rate of water is the same, the difference between the area of the section of the inner tube and the area of the interstice between the pipes in which the water flows back to the cooler, induces a different speed of the fluid in the two hydraulic lines. The characteristics of the innovative pipelines are shown in Table 1.

The hydraulic network, having a total length of $112 \mathrm{~m}$, consisted of a series of 4 benches in which four hydraulic lines, $28 \mathrm{~m}$ long, were arranged in parallel. The connection pipes between the benches were insulated with neoprene to prevent heat absorption.

The cooling system was completed by:

a) an air cooled water chiller;

b) a thermocouple sensor for cooling plant management, placed inside the greenhouse above the aerial part of the crop;

c) a thermocouple sensor for cooling plant management, placed into the substrate at the centre of the hydraulic line (Figure 2, position $2)$;

d) an electric power meter $(\mathrm{kWh})$.

In order to compare the innovative system with the traditional one, a second cooling system was set up within the same greenhouse. It was completely independent from the innovative system and a cooling plant of the same model was used (Figure 1 and 2). This traditional system was realized by a unique Polyethylene (PE) pipeline (diameter $32 \mathrm{~mm}$ )

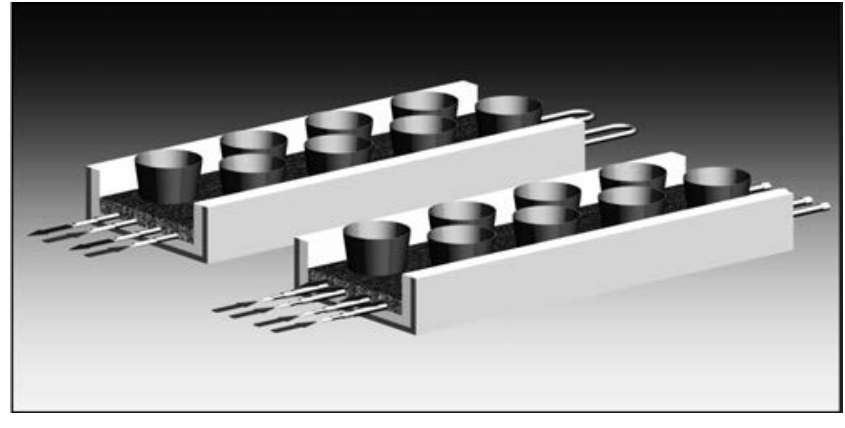

Figure 1. Water flow in winter using condition (heating mode) in the traditional (left) and in the innovative (right) system placed below the pot cultivation.

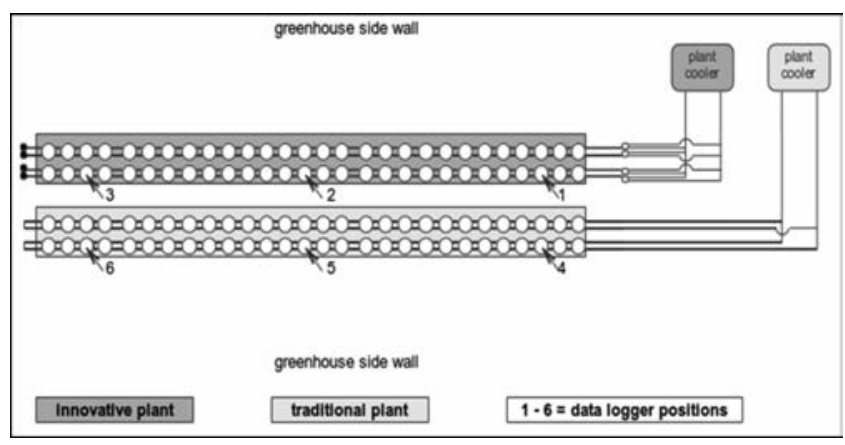

Figure 2. Scheme of the cooling systems with the position of data loggers

Table 1. Main characteristics of coaxial pipes

\begin{tabular}{lcc} 
Characteristics & $\begin{array}{c}\text { Return line } \\
\text { (outer tube) }\end{array}$ & $\begin{array}{c}\text { Delivery line } \\
\text { (inner tube) }\end{array}$ \\
External diameter $(\mathrm{mm})$ & 16.0 & 32.0 \\
Inner diameter $(\mathrm{mm})$ & 12.5 & 23.2 \\
\hline Tube section area (mm2) & 122.7 & 422.7 \\
Area of the interstice between the pipes $\left(\mathrm{mm}^{2}\right)$ & 122.7 & 221.7 \\
\hline
\end{tabular}

Table 2. CV and energy consumption.

\begin{tabular}{|c|c|c|c|c|c|c|}
\hline innovative plant operation mode & $\begin{array}{l}\text { Counter } \\
\text { current }\end{array}$ & $\begin{array}{l}\text { Counter } \\
\text { current }\end{array}$ & $\begin{array}{l}\text { Counter } \\
\text { current }\end{array}$ & $\begin{array}{l}\text { Counter } \\
\text { current }\end{array}$ & $\begin{array}{l}\text { Counter } \\
\text { current }\end{array}$ & $\begin{array}{l}\text { Counter } \\
\text { current }\end{array}$ \\
\hline Starting test date & 03/08/2011 & $19 / 08 / 2011$ & $30 / 08 / 2011$ & $11 / 08 / 2011$ & $24 / 08 / 2011$ & $26 / 09 / 2011$ \\
\hline End test date & $11 / 08 / 2011$ & $24 / 08 / 2011$ & $26 / 09 / 2011$ & $19 / 08 / 2011$ & $30 / 08 / 2011$ & $04 / 10 / 2011$ \\
\hline Average CV of 3 measured points in innovative plant & 0,04 & 0,03 & 0,03 & 0,04 & 0,03 & 0,08 \\
\hline Average CV of 3 measured points in traditional plant & 0,10 & 0,09 & 0,10 & 0,11 & 0,09 & 0,06 \\
\hline Traditional system-total energy consumption (kWh/24 h) & 22,36 & 28,75 & 17,57 & 25,34 & 25,33 & 22,13 \\
\hline Innovative system-total energy consumption (kWh/24 h) & 17,38 & 27,96 & 16,94 & 24,60 & 20,36 & 21,06 \\
\hline Total energy consumption: difference (kWh/24 h) & $-4,98$ & $-0,79$ & $-0,63$ & $-0,74$ & $-4,96$ & $-1,07$ \\
\hline Total energy consumption: difference (\%) & $-21,85$ & $-2,72$ & $-7,93$ & $-2,93$ & $-20,41$ & $-4,77$ \\
\hline
\end{tabular}


that was connected to the cooler at both extremities. Thus, both the outlet and the return branch of the same pipe were located under pots.

Each of the two coolers had cooling capacity of $10.8 \mathrm{~kW}, 3 \mathrm{~kW}$ power draw and were equipped with: hermetic compressor with thermal protection, plate evaporators, condensers battery materials come from copper pipes and storage tanks of water having a function of buffer tanks for the reduction of ignitions of the compressors and to standardize the delivery water temperature. The hydraulic circuits were equipped with water circulation pump, expansion vessel, safety valve, Y-strainer to retain impurities contained in the water circuit.

The fan groups were constituted by helical fans in thermoplastic material, directly driven by single-phase asynchronous electric motors. The cooling circuits were made of copper pipe with welded joints silver alloy comprising capillary or thermostatic expansion valve with external equalizer that modulates the flow of gas as a function of the cooling load.

There were pressure fixed setting, mechanical filters driers able to retain moisture and impurities present in the circuit, differential pressure between the inlet and outlet of the evaporator with the function of flow switches.

There were present also the switchboards, for the protection and control in accordance with International Standard IEC60335-2-40, which included a microprocessor which, among other things, served to control the water temperature and the setting of the set of operation.

The coolers were able to cool output water up to a temperature of $7^{\circ} \mathrm{C}$. Each of the 8 benches ( 4 heated by the innovative system, 4 by the traditional one) contained 2 rows of 12 plastic pots (diameter $30 \mathrm{~cm}$, volume 18.5 l) (Figure 2) placed directly above the radiant pipes. The empty spaces between pots inside the benches were filled with a $15 \mathrm{~cm}$ layer of medium-thickness expanded clay.

The temperature, in different positions along the cooling lines, was measured through the use of specific data logger with 2-channel, model Testo 175-T2 (Testo AG, Germany), with internal and external sensors. The instruments were placed in three positions along the pipelines: at the start (Figure 2, position 1 and 4), in the middle (Figure 2, position 2 and 5) and at the end (Figure 2, position 3 and 6) of the coaxial and the traditional system respectively. The data logger were synchronized to the solar time and were programmed to acquire data every 15 minutes.

In the 2011 summer season, the two cooling systems were set up and observation tests were carried out on the efficiency of the different plants. With the aim to test the cooling systems in real operating conditions, two bulbs of Zantedeschia aethiopica were previously transplanted into each pot, filled with peat and pumice, in October 2010. This species was chosen because, in order to obtain the flowering in the summer season, the temperature of the culture substrate must be constantly maintained at about $14^{\circ} \mathrm{C}$.

Temperature data were acquired by a PC and were organized in the form of a database together with the consumption of liquefied petroleum gas (LPG) and electricity for both systems.

For the analysis of the uniformity of root zone cooling, contemporaneous records of temperatures in three different positions of each line were used.

The measures obtained by data logger placed near the thermocouple sensors into the pots in the central positions 2 and 5 (Figure 2) were taken as reference to evaluate differences with the measures recorded by data loggers placed at the beginning and at the end of both systems.

In the course of 24 hours the soil temperature varied under the influence of many external factors (solar radiation, heating the greenhouse, irrigation, etc..), and so the sum of substrate temperature differences between individual measures recorded in three different points into the bench in both systems was calculated. The electrical energy consumption was recorded for each cooling plant.
In the course of the comparative tests carried out in the winter of 2007-2008, coaxial plant heating, due to operational differences between the two systems in terms of inertia in the achievement of the thermal regime, during periods in which they alternated days characterized by temperatures daily myths and nights with cold temperatures (between late autumn and early winter or late winter and early spring), presented in consumption higher than those in the traditional plant.

To resolve this problem, it has been designed and built a prototype device with hydraulic valve that can change the direction of fluid flow in coaxial pipes, allowing you to transform the mode of operation according to the Italian Patent No. 1351132 (hydraulic flows countercurrent) or according to the traditional type (hydraulic flows cocurrent) and vice versa, with regard to these critical periods characterized by intermittent operation.

Upstream of each pair of patented devices of coaxial coupling have been inserted two three-way valves which allow the orientation in the same direction of the flow of fluids in the two coaxial tubes, thus allowing to transform the operation of two pairs of coaxial pipes from the traditional to the innovative type, and vice versa.

After actuation of the valves, the water flow within the coaxial pipes occurs in the same direction (cocurrent) in the inner pipe and the external one. Obviously, to enable the return of water to the boiler, the coaxial pipes, which originally had an end cap on the external pipe, were hydraulically connected in pairs with a pipeline with a diameter equal to that of the external tube, equipped with a valve that must be kept open for operation in the traditional mode and closed for the coaxial.

During year 2011, since August 4 to October 10, the two hydraulic systems (traditional and innovative) were tested in root zone cooling function. Moreover, in consequence of the changes described above, the new coaxial system has been tested also in the cocurrent mode, which corresponds to the operation mode of the traditional plant.

To evaluate the total energy consumption of the systems compared, the data related to electricity consumption $(\mathrm{kWh})$ detected during the tests were converted to units of energy $(\mathrm{J})$ at a rate of $3.6 \mathrm{MJ} / \mathrm{kWh}$, in reference a time duration of periods of tests and evidence and expressed in MJ consumed within 24 hours (MJ / d).

\section{Results}

In table 2 , the data referred to the average $\mathrm{CV}$ of the 3 measured points of the plants indicate that from day 04/08/2011 to 4/10/2011 the innovative plant, in any mode would be used, has always obtained good conditions of cooling uniformity in the terrain of culture, compared to traditional plant. In fact, in the period from day 11/8/2011 to 19/8/2011 the average $\mathrm{CV}$ value of the 3 temperatures in innovative plant (coax mode, cocurrent) is 0,04 while in the traditional system is 0,11 .

In the period from day $24 / 8 / 2011$ to $30 / 8 / 2011$ the same values were equal to 0,03 and 0,09 respectively. In the period from day $26 / 9 / 2011$ to $4 / 10 / 2011$ values were 0,08 and 0,06 .

This shows that, for each test of the cooling plants, the traditional system showed much higher values than the innovative one. Since a higher value corresponds to a less uniformity in temperature recorded along the pipeline, it appears that the innovative system allows a greater uniformity in cooling the cultural substrate along the bench than the traditional one.

The results show that the innovative system, in relation to his functional characteristics, always consumed lower amounts of energy compared to the traditional one, ranging from $2,72 \%$ to $21,85 \%$. 


\section{Conclusions}

An innovative root zone cooling system was described and tested in this work. The main objective of this research, consisting in obtaining as homogeneous as possible temperature conditions in protected crop cultivation in relation to the different distances from the cooler, was achieved. The results of the trials carried out during year 2011 showed that the new root zone cooling system resulted in a much higher temperature uniformity than in the traditional one. The goal achieved is even more interesting considering that the innovative system also showed a lower energy consumption compared to the traditional one.

\section{References}

Carnavos, T.C., 1985. Coaxial finned tube heat exchanger, Noranda Metal Industries, Inc. (Newton, CT) United States Patent $n^{\circ}$ 4554969

Diver S., 2002. Root zone heating for greenhouse crops. Appropriate Technology Transfer fo Rural Areas (ATTRA). http:/www.attra.org/ attra-pub/ghrootzone.html

Edwards, R.C., 1981. Coaxial tube in tube heat exchanger with inner tube support, Edwards Engineering Corporation (Pompton Plains, NJ) United States Patent $n^{\circ} 4286653$
Fedrizzi, M., and Bozzoli, M., 2006. Un sistema innovativo di riscaldamento basale per colture sotto serra. Colture protette 3: 63-69

Horton, L.R., Jackson, C.A., Holcomb, W.P., and Horton, C., 1975. Coaxial Tube Coupler Assembly, United States Patent $n^{\circ} 3860269$

Roberts W. J., Mears, D. R., 1989. Floor heating of greenhouses. Acta Hort. (ISHS) 257: 189-200

Spiegelman, J.J., 1992. Coupling for interconnection of coaxial tubing, Tylan General, Inc. (San Diego, CA) United States Patent $n^{\circ}$ 5088774

Takakura T., Manning T. O., Giacomelli G. A. , Roberts W. S., 1994. Feedforward control for a floor heat greenhouse. Transactions of the ASABE. 37(3): 939-945.

Wolf, F.J., and Reichert, U., 1995. Fluid containing coaxial tube for control systems, WOCO Franz-Josef Wolf \& Co. (Bad SodenSalmunster, DE) United States Patent $n^{\circ} 5433252$

Wolf, L.W., 1996. Vented bending sleeves for coaxial tubing systems, United States Patent $n^{\circ} 5497809$

Ziemek, G., and Schatz, F., 1972. Spacing in coaxial pipes system, Kabel-und Metallwerke Gutehoffnungshutte Aktiengesellschaft (Hannover, DT) United States Patent $n^{\circ} 3670772$

Rosati, B., 2004. Nuovo tubo e valvola di flusso per una migliore gestione dell'acqua calda Italy patent $\mathrm{n}^{\circ} 0001351132$

International Standard IEC60335-2-40:2003/A13:2012 Household and similar electrical appliances - Safety - Part 2-40: Particular requirements for electrical heat pumps, air-conditioners and dehumidifiers 